\title{
COVID-19 and its impact on neurological manifestations and mental health: the present scenario
}

\author{
Shehnaz Sultana ${ }^{1} \cdot$ Venkateshwari Ananthapur $^{1}$ (B) \\ Received: 31 July 2020 / Accepted: 28 August 2020 / Published online: 31 August 2020 \\ (C) Fondazione Società Italiana di Neurologia 2020
}

\begin{abstract}
Though the COVID-19 pandemic primarily affects pulmonary and cardiorenal functions, many healthcare and its allied groups reported neurological involvement of SARS-CoV-2 in combination with either pre-existing metabolic abnormalities, medical conditions, infections or even chronic to acute inflammatory episodes of the nervous system. The present review provides a fair outlook of the published literature and also the case reports with an emphasis on plausible mechanisms involved in neurological complications of the central and peripheral nervous systems. Awareness on the neuropsychiatric manifestations being discussed in this article should ideally help the medical community in early identification and effective management of potentially lifethreatening neurological diseases.
\end{abstract}

Keywords COVID-19 $\cdot$ Neurological manifestations $\cdot$ Cerebrovascular disease $\cdot$ Stroke $\cdot$ Cytokine storm $\cdot$ Stress

\section{Introduction}

COVID-19, a severe acute respiratory syndrome (SARS) caused by SARS-CoV-2, emerged in China and advanced into a global pandemic infecting more than 22 million people globally while causing over 793,763 deaths and counting [1]. Seventy percent of the COVID-19 patients show mild to moderate respiratory symptoms, while the rest progress into severe to fatal respiratory and systemic illnesses depending on the personal genetic makeup, extent or phase of infection and inadequate management. Historically, various strains of coronaviruses are found to have neurotropism and neuroinvasive characteristics resulting in neuro and psychological consequences in a subset of COVID-19 affected population. And majority of the deaths are due to respiratory failure which is a pathophysiological consequence of a comprised brainlung-brain axis wherein neurological dysfunction and lung injury are mutually inclusive.

Venkateshwari Ananthapur

venkateshwari@yahoo.com

1 Department of Cell Biology, Institute of Genetics and Hospital for Genetic Diseases, Osmania University, Begumpet,

Hyderabad, Telangana 500016, India

\section{Mechanism of nervous system invasion}

Our understanding over time on this opportunistic pathogen has elucidated its prominent involvement in respiratory and its allied systems including cardiovascular and renal systems. Once in the blood stream, the SARS virus can spread into central and peripheral nervous systems through retrograde axonal transport or infection of the pericytes and astrocytes that are part of blood-brain barrier (BBB). Neuro-invasion of SARS-CoV-2 may also be via the olfactory nerve or infection of vascular endothelium or even the infected leukocyte migration across the blood-brain barrier (BBB). Once entering the CNS through the compromised BBB, SARS-CoV-2 virus disseminates progressively along the neurotransmission or haematogenous pathways such as serotonergic dorsal raphe system or the Virchow-Robin spaces, respectively. Neuroinvasive potential of SARS-CoV-2 particularly into the medullary structures including brain stem involved in the respiration might influence high incidence of respiratory failure in COVID-19 patients [2].

Kanberg et al. provided an evidence of central nervous system (CNS) damage in COVID-19 patients by using serological biomarkers. Plasma levels of glial fibrillary acidic protein (GFAP) and neurofilament light chain (NfL) markers of astrocytic and neuronal injury were measured in 47 COVID-19 patients. Initially elevated levels were reported in both markers in 18 patients with severe 
COVID-19, later GFAP levels declined subsequently and $\mathrm{NfL}$ levels increased continuously. Increased levels of plasma GFAP were reported in 9 patients with moderate COVID-19. This phenomenon indicates early involvement astrocytes and delayed axonal injury [3].

Coolen et al. performed MRI on 19 COVID-19 patients within $24 \mathrm{~h}$ of death. Their study reveals some interesting findings wherein parenchymal abnormalities including white matter changes, posterior reversible encephalopathy syndrome and haemorrhage in four individuals might be due to the breakdown of blood-brain barrier and may not imply direct involvement of SARS virus. Also, the study showed an evidence of olfactory bulb asymmetry, a possible MRI correlate of anosmia in other four patients [4]. Although the studies have provided the evidence of central nervous system involvement in COVID-19 patients, whether the manifestations are a direct consequence of SARS viral infection of the brain tissue is still abstruse.

\section{Angiotensin-converting enzyme 2 (ACE2) receptor role in the entry of SARS-CoV-2}

ACE2 receptor is used by SARS-CoV-1 and SARS-CoV-2 to infect the ciliated bronchial epithelial cells and type II pneumocytes. Affinity of SARS-CoV-2 is higher for ACE2 receptor compared with SARS-CoV-1, which is present in endothelial cells and neurons indicating the higher neuroinvasive potential of SARS-CoV-2 [5]. Spike protein surface unit 1 of SARS-CoV-2 has higher binding affinity to the human receptor angiotensin-converting enzyme 2 (ACE2). The SARS-CoV-2 virus shares close sequence homology to SARS-CoV-1. Both viruses use spike proteins on the viral surface to bind to the angiotensin-converting enzyme 2 (ACE2) receptor on mammalian host cells and then use serine protease transmembrane protease serine 2 (TMPRSS2) to prime the spike. ACE2 is a metalloproteinase detected in the central nervous system (CNS) especially in the brainstem and regions responsible for regulating cardiovascular functions such as subfornical organ (SFO), paraventricular nucleus $(\mathrm{PVN})$, nucleus of the tractus solitarius (NTS) and the rostral ventrolateral medulla; ACE2 is also expressed both in neurons and astrocytes [6]. According to the speculation of $\mathrm{Li}$ et al., COVID-19 infection may precipitate the changes in gut microbial composition and involves in the pathogenesis of neuropsychiatric symptoms via the gut brain axis [7].

\section{Pathophysiology}

Multiple clinical manifestations localized to PNS and CNS have been associated with SARS-CoV-2 infection notably anosmia, hypogeusia, myalgia, malaise, headache, dizziness,
Guillain-Barre syndrome, impaired consciousness, epilepsy, vision loss, encephalitis related fever and acute cerebrovascular disease. These mild to severe clinical manifestations are purportedly the consequences of direct or indirect viral invasion into the nervous system followed by immunological reactions, inflammation and hypoxia mediated metabolic changes. Headache and dizziness are the most common central nervous system (CNS)-related symptoms with epilepsy, acute cerebrovascular disease, impaired consciousness and ataxia. Ischemic or haemorrhagic stroke, muscle injury and adjusted mental status are seen in severe cases. The most common symptoms related to peripheral nervous system (PNS) are hypogeusia and hyposmia with vision impairment and neuropathic pain [8]. COVID-19 patients suffer from severe hypoxia and viremia, which have the ability to cause toxic encephalopathy [9]. The first case of viral encephalitis caused by SARS-CoV-2 attacking the central nervous system (CNS) was reported in Beijing Hospital, which was confirmed by the presence of SARS-CoV-2 in the cerebrospinal fluid by genome sequencing [10].

\section{Hypoxic injury}

SARS-CoV-2 infection causes respiratory insufficiency with subsequent establishment of hypoxia. This hypoxic state coupled with hypercapnia, peripheral vasodilatation, anaerobic metabolism and accumulation of toxic metabolites can potentially induce cerebral injury due to the development of neural swelling and cerebral oedema [11]. Isaac Solomon and his colleagues conducted the first study by combining neuropathological techniques in combination with immunohistochemistry and reverse transcriptase quantitative PCR (RTqPCR) to examine post-mortem brain tissue from 18 patients with COVID-19. They reported marked neuropathological changes that are consistent with hypoxic injury, while immunohistochemistry and RT-qPCR revealed minimal evidence of SARS-CoV-2 infection. Hypoxic changes can be attributed to patient-specific comorbidities and secondary effects due to immune complexes and inflammatory mediators from viral infection [12]. Delirium, cognitive deficits and behavioural abnormalities are caused by systemic inflammation associated with prolonged hypoxia inducing a persistent and uncontrolled neuroinflammation which is responsible for the damage of hippocampus and cortical areas associated with cognitive functions and behavioural alterations [13].

\section{Immune-mediated injury}

The first line of defence in viral infections is innate immunity, natural killer cells and type I interferons [14]. Humoral immunity involving antibodies and cytotoxic $\mathrm{T}$ cells provides adaptive immune responses towards infections and abnormal cells. When both innate and adaptive barriers are breached and 
inflammation sets in by SARS-CoV-2, the immune system initiates a substantial systemic inflammatory storm with a massive release of cytokines, chemokines and other inflammation mediators with subsequent break-through of bloodbrain barrier (BBB), which in turn leads to the amplification of neuroinflammatory processes. Systemic inflammation regardless of its nature typically compromises the blood-brain barrier (BBB), injures glia limitans and activates Toll-like receptors of astrocytes, ultimately leading to CNS inflammation that possibly might disturb brain homeostasis and neuronal death [15].

\section{Neurological manifestations of SARS-CoV-2}

The first presumptive case of acute necrotizing haemorrhagic encephalopathy in COVID-19 was reported by Poyiadji et al., which might be due to cytokine storm [16]. Interleukin-6 (IL6) does play a prominent role in cytokine storm that influences the extent of acute respiratory distress syndrome and nervous system damage [17]. Consequently, the cytokine storm may lead to a surge in interleukin-2 (IL-2), interleukin-7 (IL-7), interferon- $\gamma$ (IFN-g), inducible protein 10 (IP-10/ CXCL10), monocyte chemoattractant protein 1 (MCP-1/ CCL2), macrophage inflammatory protein $1-\alpha$ (MIP-1 $\alpha /$ CCL3) and tumour necrosis factor- $\alpha$ (TNF- $\alpha)$ resulting in hyperinflammation [18]. Antibody-mediated inflammation [19] and low lymphocyte count were observed in patients with neurological symptoms indicating weaker response of the immune system and a greater risk towards aggressive clinical manifestations [8]. The neurological manifestations share clinical, laboratory and imaging similarities with those of chimeric antigen receptor-T cell-related encephalopathy [20].

Increased prothrombin time and coagulopathy are reported in COVID-19 patients which might contribute to thrombosis or haemorrhage [21]. SARS-CoV-2 binds to ACE2 receptors on the blood vessels and increases the luminal pressure of cerebral vessels which may lead to intracerebral haemorrhage [22]. Coagulation dysfunction such as thrombocytopenia and increased D-dimer levels are the risk factors for intracranial haemorrhage in COVID-19 patients [23]. According to Beyrouti et al., five out of six acute ischaemic stroke patients with COVID-19 infection had positive lupus anticoagulant, and one patient showed medium-titre $\operatorname{IgM}$ anticardiolipin and low-titre IgG and IgM anti- $\beta 2$-glycoprotein- 1 antibodies. IgG levels are risk factor for severe COVID-19 [24]. Elevated levels of pro-inflammatory interleukins and S100B were observed in elderly patients suffering from delirium.

A study from Beijing Hospital reported headache in $6.5 \%$ of the cases [25], whereas in Wuhan 6 to8\% of the cases reported headache [2]. Mao et al. reported that $36.4 \%$ of the COVID-19 patients showed neurological disorders, of which $8.9 \%$ are of peripheral and $24.8 \%$ are of central nervous system origin; minority of cases $(10.7 \%)$ were accounted for skeletal muscle injuries. Moriguchi et al. reported SARSCoV-2 RNA in cerebrospinal fluid (CSF) of COVID-19 patient with acute neurologic symptoms including seizures [26]. In contrast, Duong et al. and Ye et al. reported meningitic and encephalitic pathology in the severe COVID-19 patients even in the absence of virus detection in cerebrospinal fluid (CSF) $[27,28]$. Andrea et al. reported a case with mild respiratory illness developed an akinetic mutism attributable to encephalitis [29]. Narges et al. presented a case of frequent seizures in 30-year-old COVID-19 patient with no past medical history [30]. Multifocal transverse myelitis after COVID-19 infection is reported by Maike et al., in a 60-year-old patient [31]. Guillain-Barre syndrome (GBS) was reported in a 65-yearold COVID-19-infected patient [32]. Donatella et al. reported a case of Guillain-Barre syndrome (GBS) in an Italian patient [33]. Paola et al. reported a possible correlation between acute COVID-19 infection and Guillain-Barre syndrome (GBS) [34]. Consuelo et al. reported two rare cases of Miller Fisher syndrome and polyneuritis cranialis in COVID-19 patients [35]. Skeletal muscle injury in COVID-19-infected patients is reported by Guan et al., 14.9\% of the cases represented myalgias; creatinine kinase (CK) levels were higher in $19 \%$ severe cases and $12.5 \%$ in non-severe [36]. The exact underlying mechanism of skeletal muscle injury in SARS-COV-2 patients is yet to be known, which warrants further studies.

According to the retrospective study of $\mathrm{Li}$ et al., from Wuhan, a new onset of cerebrovascular disease is observed in 13 COVID-19 patients. Eleven patients were diagnosed with ischemic stroke and the rest of the two with cerebral haemorrhage and cerebral venous sinus thrombosis (CVST) [2]. Stroke was developed in four elderly patients diagnosed with COVID-19, and large vessel disease was the mechanism of vascular damage [37]. COVID-19 infection was associated with coagulopathy causing venous and arterial thrombosis [38]. Beyrouti et al., from National Hospital for Neurology and Neurosurgery, London, reported demographic, clinical, radiological and laboratory characteristics of six acute ischaemic stroke patients with COVID-19 infection. All the six patients had large vessel occlusion with markedly elevated Ddimer levels $(\geq 1000 \mu \mathrm{g} / \mathrm{L})$. Multi-territory infarcts were reported in three patients; two had concurrent venous thrombosis, and other two patients suffered ischaemic stroke despite therapeutic anticoagulation [24]. Julie et al. reported neurologic features in 7 (12\%) COVID-19 patients out of 58 patients admitted to intensive care units in Strasbourg, France. In all of these cases mentioned thereof, acute respiratory distress syndrome (ARDS) due to SARS-CoV-2 infection was associated with encephalopathy, prominent agitation, confusion and corticospinal tract signs.

Seyed et al. reported a case of focal cerebral arteriopathy and ischemic stroke in a paediatric COVID-19 patient presenting with seizure, right hemiparesis and dysarthria; the child 
was tested positive for SARS-CoV-2 both from nasopharyngeal swab and cerebral spinal fluid [39]. Large vessel stroke is reported in five COVID-19-infected patients younger than 50 years by Oxley et al. [40]. Autopsy reports of deceased COVID-19 patients revealed brain tissue oedema and partial neuronal degeneration [23]. Badrul et al., from Indonesia, reported neurological manifestations in $3-4 \%$ out of 114 COVID-19-infected patients; thrombotic stroke was the most common followed by myeloid tumours and hypoxic-ischemic encephalopathy (HIE) [41]. Farzad et al. reported a series of six patients younger than 55 years of age affected with COVID-19 and diagnosed with stroke. Brain CT scan findings of the patients revealed right middle cerebral artery (MCA) infarction $(n=3)$, left MCA $(n=2)$ and left basal ganglia infarction $(n=1)$, and the majority of the patients had large vessel stroke [42].

\section{Psychological impact of COVID-19}

The emergence of COVID-19 pandemic pressed distress around illness, death and uncertainty about the future among the population with a consequential disturbance in psychosocial behaviour, affecting a remarkable proportion of population worldwide. Social distancing, loss of structured educational framework and altered employment arrangements are the additional contributors towards undesirable mental health [43].

Neuroinflammation and prolonged hypoxia may promote neuropsychiatric sequelae and cognitive impairments. Neuroinflammation has always been an important feature in mounting neurodegenerative disorders and psychiatric pathologies such as acute psychosis and schizophrenia and other associated disorders [44]. And secondary immunological changes may influence furthering the neuropsychiatric events into a chronic phase [45]. Stress would consequentially activate hypothalamic pituitary-adrenal axis, releasing increased levels of steroids that impair the immune system functioning and precipitate the infection causing exacerbations of neuro and psychological conditions. Undesirably, the drugs used in the treatment of COVID-19 such as oseltamivir, corticosteroids and interferons may promote psychiatric symptoms [46]. Sato et al. reported neuropsychiatric effects like amnesia, delirium, hallucinations, depression and loss of consciousness with exposure to chloroquine [47]. Recent studies have reported the neuropsychiatric burden [48] caused due to COVID-19 that include encephalopathy [30], delirium [16, 26, 29], mild cognitive impairment [49], mood swings [50], insomnia [51] and psychosis [47].

A study on the psychological impact of COVID-19 in Spanish population disclosed that about $19 \%$ were positively diagnosed with depression and around $22 \%$ were likely to be diagnosed with anxiety; among which, women showed greater depressive symptoms such as anxiety and post-traumatic stress disorder (PTSD), whereas personal economic situation, retirement and old age played a stimulating role towards developing depression, anxiety and PSTD [52]. A meta-analysis from Asian countries on the impact of COVID-19 pandemic on mental health showed prevalence of anxiety and depression in $20 \%$ of the population with varying degrees according to gender and vocation [53]. A study from Basque had found a greater psychological impact on younger people and those with pre-existing illnesses [54]. Unjustified fear of SARS$\mathrm{CoV}-2$ infection leads to higher anxiety in general population and in individuals with pre-existing mental illnesses resulting in discrimination and stigmatization [55]. Post-traumatic stress syndrome (PTSD) prevalence is in between 4 and $41 \%$ in general population, while the prevalence of depression increased by $7 \%$ after the emergence COVID-19. Female sex, poor socioeconomic status, interpersonal conflicts, frequent social media exposure and inadequate social support are some of the influential factors showing significant impact on overall mental health status [54]. Development and implementation of mental health screening and intervention programmes for both the public and for healthcare workers is being insisted by Bao et al. [56].

\section{Conclusion}

In conclusion, taking the global scenario of COVID-19 and fatalities into consideration, it is important to tackle the issue through a multidisciplinary approach. The proportion of COVID-19 patients with neurological manifestations is low compared with respiratory disease. However, taking into account the recent reports on neurological manifestations in COVID-19 patients, it is of utmost importance to diagnose the direct and indirect neurotropic effects SARS-CoV-2 and its secondary impacts on nervous system. Though the exact neuropsychiatric burden of COVID-19 is yet to be deciphered, it is anticipated to have a significant impact on global population for many years to come. Paying an up-close attention to the neurological and psychiatric consequences of SARS-CoV-2 is highly warranted for early and effective management of the condition through therapeutic strategies and rehabilitation programmes. To combat with COVID-19 pandemic and improve the mental state of the population, emphasis should be given to reduce extreme fear and negative social attitude by creating awareness among the people. Priority should be given to vulnerable populations such as infected, sick patients and respective immediate their families and colleagues.

Acknowledgements The authors would like to thank Mr. Samuel Abraham Joshi Davala for English language editing of the review article.

Authors' contribution Idea for the review, literature search and drafting are done by Shehnaz Sultana. Venkateshwari Ananthapur revised the work and approved the version to be published. 
Data availability Not applicable.

\section{Compliance with ethical standards}

Conflict of interest The authors declare that they have no conflict of interest.

Ethics approval Not applicable.

Consent to participate Not applicable.

Consent to publication Both the authors have consented for publication of the review article.

Code availability Not applicable.

\section{References}

1. Johns Hopkins University Coronavirus Resource Center: https:// coronavirus.jhu.edu

2. Li Y, Wang M, Zhou Y, et al (2020) Acute cerebrovascular disease following COVID-19:A single center, retrospective, observational study, Lancet https://papers.ssrn.com/sol3/papers.cfm?abstract_id= 3550025/

3. Kanberg N, Ashton NJ, Andersson LM, Yilmaz A, Lindh M, Nilsson S, Price RW, Blennow K, Zetterberg H, Gisslén M (2020) Neurochemical evidence of astrocytic and neuronal injury commonly found in COVID-19. Neurology. https://doi.org/10. 1212/WNL.0000000000010111

4. Coolen $\mathrm{T}$ et al (2020) Early postmortem brain MRI findings in COVID-19 non- survivors. Neurology. https://doi.org/10.1212/ WNL.0000000000010116

5. Natoli S, Oliveira V, Calabresi P, Maia LF, Pisani A (2020) Does SARS-Cov-2 invade the brain? Translational lessons from animal models. Eur J Neurol 27:1764-1773. https://doi.org/10.1111/ene. 14277

6. Gowrisankar YV, Clark MA (2016) Angiotensin II regulation of angiotensin-converting enzymes in spontaneously hypertensive rat primary astrocyte cultures. J Neurochem 138(1):74-85. https://doi. org/10.1111/jnc.13641

7. Li N, Ma WT, Pang M, Fan QL, Hua JL (2019) The commensal microbiota and viral infection: a comprehensive review. Front Immunol 10:1-16. https://doi.org/10.3389/fimmu.2019.01551

8. Mao L, Jin H, Wang M, Hu Y, Chen S, He Q, Chang J, Hong C, Zhou Y, Wang D, Miao X, Li Y, Hu B (2020) Neurologic manifestations of hospitalized patients with coronavirus disease 2019 in Wuhan, China. JAMA Neurol 77:683. https://doi.org/10.1001/ jamaneurol.2020.1127

9. Guo YR, Cao QD, Hong ZS, Tan YY, Chen SD, Jin HJ et al (2020) The origin, transmission and clinical therapies on coronavirus disease 2019 (COVID-19) outbreak - an update on the status. Mil Med Res 7(1): 11

10. Xiang $\mathrm{P}, \mathrm{Xu} \mathrm{XM}$, Gao LL, Wang HZ, Xiong HF, Li RH, et al (2020) First case of 2019 novel coronavirus disease with encephalitis. ChinaXiv T202003, 00015

11. Tu H, Tu S, Gao S, Shao A, Sheng J (2020) Current epidemiological and clinical features of COVID-19; a global perspective from China. J Inf Secur 81:1-9. https://doi.org/10.1016/j.jinf.2020.04. 011

12. Solomon IH, Normandin E, Bhattacharyya S, Mukerji SS, Keller K, Ali AS, Adams G, Hornick JL, Padera RF Jr, Sabeti P (2020)
Neuropathological features of Covid-19. N Engl J Med. https:// doi.org/10.1056/NEJMc2019373

13. Sasannejad C, Ely EW, Lahiri S (2019) Long-term cognitive impairment after acute respiratory distress syndrome: a review of clinical impact and pathophysiological mechanisms. Crit Care 23(1): 352

14. Koyama S, Ishii KJ, Coban C, Akira S (2008) Innate immune response to viral infection. Cytokine 43:336-341

15. Sankowski R, Mader S, Valdes-Ferrer SI (2015) Systemic inflammation and the brain: novel roles of genetic, molecular, and environmental cues as drivers of neurodegeneration. Front Cell Neurosci 9:28

16. Poyiadji N, Shahin G, Noujaim D, Stone M, Patel S, Griffith B (2020) COVID-19-associated acute hemorrhagic necrotizing encephalopathy: CT and MRI features. Radiology 201187. https:// doi.org/10.1148/radiol.2020201187

17. Hirano T, Murakami M (2020) COVID-19: a new virus, but a familiar receptor and cytokine release syndrome. Immunity 52 : 731-733. https://doi.org/10.1016/j.imunni.2020.04.003

18. Mehta P, McAuley DF, Brown M, Sanchez E, Tattersall RS, Manson JJ (2020) COVID-19: consider cytokine storm syndromes and immunosuppression. Lancet 395:1033-1034. https://doi.org/ 10.1016/S0140-6736(20)30628-0

19. Iwasaki A, Yang Y (2020) The potential danger of suboptimal antibody responses in COVID-19. Nat Rev Immunol 20:339-341

20. Perrin P, Collongues N, Baloglu S et al (2020) Cytokine release syndrome-associated encephalopathy in patients with COVID-19. Preprint June 2020. https://doi.org/10.20944/preprints202006. 0103.v1

21. Wang W, Tang J, Wei F (2020) Updated understanding of the outbreak of 2019 novel coronavirus $(2019-\mathrm{nCoV})$ in Wuhan, China. J Med Virol 92(4):441-447. https://doi.org/10.1002/jmv. 25689

22. Wu Y, Xu X, Chen Z, Duan J, Hashimoto K, Yang L, Liu C, Yang C (2020) Nervous system involvement after infection with COVID19 and other coronaviruses. Brain Behav Immun 87:18-22. https:// doi.org/10.1016/j.bbi.2020.03.031

23. Nile SH, Nile A, Qiu J, Li L, Jia X, Kai G (2020) COVID-19: pathogenesis, cytokine storm and therapeutic potential of interferons. Cytokine Growth Factor Rev 53:66-70. https://doi.org/10. 1016/j.cytogfr.2020.05.002

24. Beyrouti R, Adams ME, Benjamin L, Cohen H, Farmer SF, Goh YY, Humphries F, Jäger HR, Losseff NA, Perry RJ, Shah S, Simister RJ, Turner D, Chandratheva A, Werring DJ (2020) Characteristics of ischaemic stroke associated with COVID-19. J Neurol Neurosurg Psychiatry 0:1-3. https://doi.org/10.1136/jnnp2020-323586

25. Tian S, Hu N, Lou J, Chen K, Kang X, Xiang Z, Chen H, Wang D, Liu N, Liu D, Chen G, Zhang Y, Li D, Li J, Lian H, Niu S, Zhang L, Zhang J (2020) Characteristics of COVID-19 infection in Beijing. J Inf Secur 80:401-406. https://doi.org/10.1016/j.jinf.2020.02.018

26. Moriguchi T, Harii N, Goto J, Harada D et al (2020) A first case of meningitis/encephalitis associated with SARSCoronavirus-2. Int $\mathrm{J}$ Infect Dis. https://doi.org/10.1016/j.ijid.2020.03.062

27. Duong L, Xu P, Lu A (2020) Meningoencephalitis without respiratory failure in a young female patient with COVID-19 infection in downtown Los Angeles, Early Brain Behav Immun

28. Ye M, Ren Y, Lv T (2020) Encephalitis as a clinical manifestation of COVID-19. Brain Behav Immun 88:945-946

29. Pilotto A, Odolini S, Masciocchi S et al (2020) Steroid responsive encephalitis in Covid-19 disease. Ann Neurol. https://doi.org/10. 1002/ana.25783

30. Karimi N, Razavi AS, Rouhani N (2020) Frequent convulsive seizures in an adult patient with COVID-19: a case report. Iran Red Crescent Med J 22(3):e102828. https://doi.org/10.5812/ircmj. 102828 
31. Munz M, Wessendorf S, Koretsis G, Tewald F, Baegi R, Krämer S, Geissler M, Reinhard M (2020) Acute transverse myelitis after COVID-19 pneumonia. J Neurol 267:2196-2197. https://doi.org/ 10.1007/s00415-020-09934-w

32. Sedaghat Z, Karimi N (2020) Guillain Barre syndrome associated with COVID-19 infection: a case report. J Clin Neurosci 76:233235

33. Ottaviani D, Boso F, Tranquillini E, Gapeni I, Pedrotti G, Cozzio S, Guarrera GM, Giometto B (2020) Early Guillain-Barré syndrome in coronavirus disease 2019 (COVID-19): a case report from an Italian COVID-hospital. Neurol Sci 41:1351-1354. https://doi. org/10.1007/s10072-020-04449-8

34. Alberti P, Beretta S, Piatti M et al (2020) Guillain-Barre syndrome related to COVID-19 infection. Neurol Neuroimmunol Neuroinflamm 7:e741. https://doi.org/10.1212/NXI. 0000000000000741

35. Gutierrez-Ortiz C, Mendez A, Rodrigo-Rey S et al (2020) Miller fisher syndrome and polyneuritis cranialis in COVID-19. Neurology. https://doi.org/10.1212/WNL.0000000000009619

36. Guan W, Ni Z, Hu Y, Liang WH, Ou CQ, He JX, Liu L, Shan H, Lei CL, Hui DSC, du B, Li LJ, Zeng G, Yuen KY, Chen RC, Tang CL, Wang T, Chen PY, Xiang J, Li SY, Wang JL, Liang ZJ, Peng YX, Wei L, Liu Y, Hu YH, Peng P, Wang JM, Liu JY, Chen Z, Li G, Zheng ZJ, Qiu SQ, Luo J, Ye CJ, Zhu SY, Zhong NS, China Medical Treatment Expert Group for Covid-19 (2020) Clinical characteristics of coronavirus disease 2019 in China. N Engl J Med 382:1708-1720. https://doi.org/10.1056/ NEJMoa20020322020

37. Avula, et al. (2020) COVID-19 presenting as stroke. Brain Behav Immun

38. Chen N, Zhou M, Dong X, Qu J, Gong F, Han Y, Qiu Y, Wang J, Liu Y, Wei Y, Xia J', Yu T, Zhang X, Zhang L (2020) Epidemiological and clinical characteristics of 99 cases of 2019 novel coronavirus pneumonia in Wuhan, China: a descriptive study. Lancet 395:507-513. https://doi.org/10.1016/S01406736(20)30211-7

39. Mirzaee SMM, Goncalves FG, Mohammadifard M et al (2020) Focal cerebral arteriopathy in a COVID-19 paediatric patient. Radiology. https://doi.org/10.1148/radiol.2020202197

40. Oxley T, Mocco J, Majidi S et al (2020) Large-vessel stroke as a presenting feature of Covid-19 in the young. N Engl J Med 382(20): e60

41. Munir B, Rianawati SB, Kurniawan SN et al (2020) Neurological manifestation on hospitalized patient with probable COVID-19 in Saiful Anwar Hospital Indonesia (Serial Cases). Malang Neurol J 6: https://doi.org/10.21776/ub.mnj.2020.006.02.1

42. Ashrafi F, Zali A, Ommi D, Salari M, Fatemi A, Arab-Ahmadi M, Behnam B, Azhideh A, Vahidi M, Yousefi-Asl M, Jalili khoshnood $\mathrm{R}$, Advani S (2020) COVID-19-related strokes in adults below 55 years of age: a case series. Neurol Sci 41:1985-1989. https://doi. org/10.1007/s10072-020-04521-3

43. Carvalho PM d M, Moreira MM, de Oliveira MNA, Landim JMM, Neto MLR (2020) The psychiatric impact of the novel coronavirus outbreak. Psychiatry Res 286:112902. https://doi.org/10.1016/j. psychres.2020.112902
44. Pape K, Tamouza R, Leboyer M, Zipp F (2019) Immunoneuropsychiatry - novel perspectives on brain disorders. Nat Rev Neurol 15(6):317-328

45. Qin C, Zhou L, Hu Z, Zhang S, Yang S, Tao Y et al (2020) Dysregulation of immune response in patients with COVID-19 in Wuhan, China. Clin Infect Dis 32161940. https://doi.org/10.1093/ cid/ciaa248. In press

46. Russell CD, Millar JE, Baillie JK (2020) Clinical evidence does not support corticosteroid treatment for 2019-nCoV lung injury. Lancet 395(10223):473-475

47. Sato K, Mano T, Iwata A, Toda T (2020) Neuropsychiatric adverse events of chloroquine: a real-world pharmacovigilance study using the FDA adverse event reporting system (FAERS) database. Biosci Trends 14(2):139-143

48. Troyer EA, Kohn JN, Hong S (2020) Are we facing a crashing wave of neuropsychiatric sequelae of COVID-19? Neuropsychiatric symptoms and potential immunologic mechanisms. Brain Behav Immun 32298803:34-39. https://doi.org/10. 1016/j.bbi.2020.04.027

49. Helms J, Kremer S, Merdji H, Clere-Jehl R, Schenck M, Kummerlen C, Collange O, Boulay C, Fafi-Kremer S, Ohana M, Anheim M, Meziani F (2020) Neurologic features in severe SARSCoV-2 infection. N Engl J Med 382:23-2270. https://doi.org/10. 1056/NEJMc2008597

50. Yin R, Feng W, Wang T, Chen G, Wu T, Chen D et al (2020) Concomitant neurological symptoms observed in a patient diagnosed with coronavirus disease 2019. J Med Virol. https://doi.org/ 10.1002/jmv. 25888

51. Hao F, Tan W, Jiang L, Zhang L, Zhao X, Zou Y, Hu Y, Luo X, Jiang X, McIntyre RS, Tran B, Sun J, Zhang Z, Ho R, Ho C, Tam W (2020) Do psychiatric patients experience more psychiatric symptoms during COVID-19 pandemic and lockdown? A casecontrol study with service and research implications for immunopsychiatry. Brain Behav Immun 32353518:100-106. https://doi.org/10.1016/j.bbi.2020.04.069

52. Gonzalez-Sanguino C, Ausin B, Castellanos MA et al (2020) Mental health consequences during the initial stage of the 2020 coronavirus pandemic (COVID-19) in Spain. Brain Behav Immun 87:172-176

53. Pappa S, Ntella V, Giannakas T, Giannakoulis VG, Papoutsi E, Katsaounou P (2020) Prevalence of depression, anxiety, and insomnia among healthcare workers during the COVID-19 pandemic: a systematic review and meta-analysis. Brain Behav Immun 88:901907. https://doi.org/10.1016/j.bbi.2020.05.026

54. Dosil-Santamaria M, Picaza-Gorrochategui M, Idoiaga-Mondragon $\mathrm{N}$ (2020) Stress, anxiety, and depression levels in the initial stage of the COVID-19 outbreak in a population sample in the northern Spain. Cad Saúde Pública 36, e00054020

55. Mowbray H (2020) In Beijing, coronavirus 2019-nCoV has created a siege mentality. Br Med J 368

56. Bao Y, Sun Y, Meng S, Shi J, Lu L (2020) 2019-nCoV epidemic: address mental health care to empower society. Lancet 395:e37e38. https://doi.org/10.1016/S0140-6736(20)30309-3

Publisher's note Springer Nature remains neutral with regard to jurisdictional claims in published maps and institutional affiliations. 